\title{
PREPARATION AND CHARACTERIZATION OF EUDRAGIT RS 100 MICROSPHERES CONTAINING CIPROFLOXACIN HYDROCHLORIDE
}

\author{
Khaled I. Saleh, Mohamed A. Amin, Gamal M. Zayed and Fahd M. EI Sharif \\ Department of Pharmaceutics and Industrial Pharmacy, Al Azhar University, Assiut.
}

\section{1- ABSTRACT}

Controlled drug delivery systems have received considerable attention in the last years as they provide a more controlled drug concentration at site of action leading to an improvement in the therapeutic outcomes. In this study, ciprofloxacin hydrochloride (Cip. $\mathrm{HCl}$ ) microspheres were prepared using Eudragit RS 100 polymer applying the emulsion solvent evaporation method. The drug polymer ratios were selected to be 1:2 and 1:3. Scanning electron microscopy (SEM), X-ray diffractometry (XRD) and differential scanning calorimetry (DSC) analysis were used to characterize the obtained microspheres as well as the yield percent (\%) and drug content. The in-vitro release patterns and the antibacterial activity of the formulated microspheres were also investigated. It was found that drug release was retarded by increasing the amount of the polymer and $\mathrm{X}$ ray diffractometry verified that there was no interaction between the drug and polymer. The antibacterial activity of the drug was improved as indicated by the increase in the inhibition zone diameter of the microsphere formulation.

\section{2- INTRODUCTION}

A great interest is focusing on the idea of replacing the frequent administration of a drug with delivery systems that release a constant effective dose to the target tissue via a controlled release mechanism (Benita, 1996). Controlled release drug delivery systems provide drug release at a predetermined, predictable, and controlled rate (Huang and Brazel, 2001). Furthermore, multiple daily dosing often is inconvenient for the patient and can result in missed doses and patient non compliance with the therapeutic regimen. (Buntner et al., 1998; Jameela et al., 1998; Durate et al., 2006). Ciprofloxacin is one of the most widely available fluoroquinolone antibiotics and has potent bactericidal activity. Ciprofloxacin is rapidly excreted after oral administration and this could be overcome by a sustained or controlled release formulation (Crump et al., 1983 and Yu et al., 1999). On the other hand, as a model drug, ciprofloxacin was encapsulated in the poly lactic acid microspheres by the phase separation technique (Yu et al., 1999). In the present study, Cip. HCl-Eudragit RS 100 microspheres were prepared via emulsion solvent evaporation method. Martinez et al. (1997) have reported the preparation of poly (DL-lactide-coglycolide,PLGA) ciprofloxacin microspheres. They used both the solvent evaporation method and the evaporation- extraction method to prepare sustained release biodegradable microspheres. The aim of this study was to prepare and characterize sustained release formulations of Cip. $\mathrm{HCl}$ using Eudragit RS 100 as a retarding agent. 


\section{3- EXPERIMENT}

\subsection{Materials}

Ciprofloxacin $\mathrm{HCl}$ (was kindly gifted by Egyptian International Pharmaceutical Industries Co., E. I. P. I. Co. $10^{\text {th }}$ of Ramadan City, Egypt), Eudragit RS 100 (Rhom Pharma, Gmbh, Weitsbadt, Germany), span 80, (Sigma Chemical Co., St. Louis, USA), liquid paraffin and magnesium stearate (El-Gomhoria Chem. Co., Cairo Egypt), cyclohexane (Sigma Chem. Co., Stoneham, Germany), acetone, hydrochloric acid, potassium dihydrogen orthophosphate, sodium hydroxide and n-hexane (El-Nasr Pharm. Chem. Co., Cairo, Egypt), Müeller-Hinton agar (Cockeys Ville, MD 21030, USA).

\subsection{Preparation of Cip. HCl microspheres by emulsion solvent evaporation method}

Cip. $\mathrm{HCl}$ was dispersed in the polymeric solution of Eudragit RS 100, previously prepared by dissolving the polymers in $20 \mathrm{ml}$ acetone, forming the internal phase. Different concentrations of the drug to the polymer were used to prepare the microspheres, namely $1: 2$ and 1:3. A known amount of magnesium stearate $(125 \mathrm{mg})$ was dispersed in the internal phase as soothing agent and to prevent droplet coalescence during solvent evaporation (Verma et al., 2010). This dispersion was added drop wise to $150 \mathrm{ml}$ of liquid paraffin (external phase) containing different concentrations of span 80 as emulsifying agent (1 and $1.5 \%$ $\mathrm{W} / \mathrm{V}$ ) and was emulsified into water in oil emulsion by stirring at different speeds namely 500 and $700 \mathrm{rpm}$ (table 1). The stirring was continued at room temperature till complete evaporation of the internal phase solvent (about 5 hours) as indicated by disappearance of acetone odor. Liquid paraffin was decanted and the microspheres produced were filtered off and washed three times with both $\mathrm{n}$ hexane and cyclohexane to remove the remaining oily phase and then dried over night at room temperature.

\subsection{Characterization of the microspheres}

\section{I- Production yield determination}

The production yield of the microspheres was determined by dividing the weight of the prepared microspheres by the original weight of the drug and polymer. The results were expressed as percentage (\%).

\section{II- Determination of drug content and loading efficiency}

Drug content of the prepared ciprofloxacin $\mathrm{HCl}$ microspheres was determined by the digestion method. (Abd El-rasoul, 2007). Cip. $\mathrm{HCl}$ microspheres $(25 \mathrm{mg})$ were crushed carefully in a glass mortar and transferred into a $100 \mathrm{ml}$ volumetric flask containing phosphate buffer $\mathrm{pH} \mathrm{7.4.} \mathrm{The} \mathrm{volumetric} \mathrm{flask}$ was completed to the volume with phosphate buffer then sonicated in a special sonicator (Wise Clean, model WUC-D $06 \mathrm{H}$, Daihan Scientific, Korea) for five minutes and left over night for the complete extraction of the drug. The sample was filtered and the drug concentration was determined spectrophotometrically at 271.5 $\mathrm{nm}$. The entrapping efficiency was determined by applying the following law:

$\%$ of Entrapping Efficiency $=$ AActual drug content $(\mathrm{mg}) /$ Theoretical drug content (mg)\} X 100. 


\section{III- Scanning Electron Microscopy (SEM) imaging}

SEM provides direct images of the particle surfaces being measured. Images of the microspheres surface were taken using JOEL-JSM- 5400 LV scanning electron microscope, (Japan).

\section{IV-X- ray diffractometry (XRD)}

The prepared microspheres, pure drug and the physical mixture (drug to polymer 1:2) were subjected to X-ray diffractometry using Philips X- Ray diffractometer, Holland.

\section{V- Differential scanning calorimetry (DSC)}

DSC studies were carried out using previously prepared Cip. $\mathrm{HCl}$ microspheres, with drug to polymer ratio 1:2, as well as the pure drug and pure polymer (Eudragit RS 100) in order to examine any kind of interaction between $\mathrm{Cip}$. $\mathrm{HCl}$ and additives. Samples of about 5 $\mathrm{mg}$ were accurately weighed and encapsulated into flat-bottomed aluminum pans with crimped on lids. The heating rate of $10{ }^{\circ} \mathrm{C} / \mathrm{min}$ from $30{ }^{\circ} \mathrm{C}$ to $350{ }^{\circ} \mathrm{C}$ was used in presence of nitrogen at flow rate of $40 \mathrm{ml} / \mathrm{min}$.

\section{VI- In-vitro release of the drug from the microspheres}

Dissolution profiles of the prepared microspheres equivalent to $100 \mathrm{mg}$ Cip. $\mathrm{HCl}$ were determined using rotating paddle (apparatus II). The paddle speed was $50 \mathrm{rpm}$ and a temperature of $37 \pm 0.5^{\circ} \mathrm{C}$ applying the $\mathrm{pH}$ shift method. (Kondo et al., 1994). Filtered samples, $3 \mathrm{ml}$ each, were removed at specified time intervals, namely $15,30,45,60,90,120,150,180,240,300,360,420$ and $480 \mathrm{~min}$. The samples were appropriately diluted with the release medium and the absorbance was measured at the predetermined $\lambda$ max of the drug in each medium against a blank of this medium.

\section{VII- Evaluation of anti-Bacterial Activity of Cip. $\mathrm{HCl}$ from the best formulation}

The antibacterial activity of pure drug and Cip. $\mathrm{HCl}$ microspheres (F5) were performed applying cup diffusion method using Müeller-Hinton agar as culture medium (according to National Committee for Clinical Laboratory Standards, NCCLS, 2002)

\section{RESULTS AND DISCUSSION}

\section{I- Production Yield Determination}

It was found that the production yield of the prepared microspheres was ranging from $(90.26 \%)$ to $(98.31 \%)$ as shown in table (2) and illustrated as histogram in figure (1). Generally, the yield of all formulations was high and the best value was for formula (4) while the worst one was for formula (8). So, the formulae were arranged, in a descending manner, as following: F4, F1, F3, F7, F6, F5, F2 and F8. The yield of microspheres was not affected by either the change in the emulsifier concentration or the drug to polymer ratio.

\section{II- Drug Content Determination}

Formula (3) gave the best drug content $(97.80 \%)$, while formula (5) showed the worst value $(73.17 \%)$ as shown in table (2) and illustrated as histogram in figure (1). The formulae could be arranged, in a descending manner, as following: F3, F7, F6, F8, F1, F4, 
F2 and F5. It was noticed that increasing the emulsifier concentration (in F3, F7 and F8) led to increase in the loading efficiency of the drug in the microspheres.

\section{III- Scanning electron microscopy}

SEM images showed that the microspheres were semispherical in shape and with smooth surface (fig. 2 a). The surface of the drug loaded microspheres manifested the presence of small pores from which release media can penetrate and drug release occurs (especially, F4 which showed large pores as shown in fig. $2_{b}$ ). Furthermore, it was revealed by SEM that F4 showed some aggregates of the produced microspheres (fig. $2_{b}$ ).

\section{IV-X- ray diffractometry}

Prominent diffraction lines of pure ciprofloxacin $\mathrm{HCl}$, Cip. $\mathrm{HCl}$-Eudragit physical mixture and powdered Cip. HCl-Eudragit microspheres were identified as shown in figure (3). Presence of all prominent diffraction peaks and absence of new peaks suggested an absence of interaction between $\mathrm{Cip} . \mathrm{HCl}$ and excipients. In addition, Cip. $\mathrm{HCl}$ peaks intensities have been relatively reduced indicating a decrease in the crystallinity and subsequent shift to the amorphous form.

\section{V- Differential scanning calorimetry (DSC)}

The thermal behavior of ciprofloxacin HCl-Eudragit RS 100 microspheres was found to be similar to that of the physical mixture with reduction in the peaks intensities and temperatures (fig. 4).On the other hand, the presence of the drug melting peaks in the prepared microspheres verified that the amount of the polymer in these systems was not enough to completely transform the drug into the amorphous form.

\section{VI- In-Vitro Release and Kinetic Studies of Ciprofloxacin HCl Microspheres}

The in-vitro releases of Cip. HCl-Eudragit RS 100 microspheres are presented as shown in table (3). Furthermore, the kinetic data for the in-vitro release of the microspheres were determined according to zero, first kinetic orders and also according to Higuchi`s diffusion model.

\section{a) Effect of the drug polymer ratio on drug release}

It was found that the drug release from the microspheres decreased by increasing the amount of the polymer (1:3). This decrease in drug release could be attributed to the formation of thicker coating membranes or due to the decrease in number of pores at the microsphere surface at higher polymer to drug ratios. Similar results (Zidan et al., 2006; Wang et al., 2007 and Salaun et al., 2008).

\section{b) Effect of the emulsifier concentration}

For formulations prepared at drug to polymer ratio of $1: 2$, it was found that as the emulsifier concentration decreased (span 80,1\%), at the same stirring rate, more drug was retained in the microspheres. So, drug release from F1 was less than that of F3 and F2 was less than that of F4.

Similarly, this effect was also investigated for formulae prepared at drug to polymer ratio of 1:3 as following; drug release from F5 was lower than that of F7 (with the same stirring rate) and F6 was less than F8 (with the same stirring rate).

\section{c) Effect of the stirring or speed rate on the drug release}

This effect was more significant for formulae prepared at drug to polymer ratio $1: 2$. It was noticed that formulae prepared at lower stirring or speed rates $(500 \mathrm{rpm})$ showed decreased rate of drug release. The rapid release of formulae F4 may be attributed to high 
speed rate, high span 80 concentration and presence of multiple pores on the surface of the formula due to high shearing rate at the higher speed (fig. $2_{b}$ ).

In calculating the kinetic parameters, the slope, the correlation coefficient, the specific rate constant and the half life were determined for each order or model as represented in table (4). It was found that the drug was released according to zero order kinetics from formulae F5, F6, F7 and F8 with $\mathrm{t}_{0.5} 5.37,5.64,5.58$ and 4.78 hours, respectively. While formulae F2 and F3 were found to be based on Higuchi diffusion model with $\mathrm{t}_{0.5} 3.04$ and 1.56 hours, respectively. Similarly, it was observed that formulae F1 and F4 followed first order kinetic with $\mathrm{t}_{0.5} 2.92$ and 1.01 hours, respectively.

\section{VII-Evaluation of Anti-Bacterial Activity of Ciprofloxacin $\mathrm{HCl}$ microspheres}

The antibacterial activity of the free drug and Cip. HCl-Eudragit RS 100 microspheres best formulation (F5) is shown in table (5) and fig. (7). The antibacterial activity of the selected formulation was studied against Escherichia coli (representing Gram negative strains) and Streptococcus faecalis (representing Gram positive strains) comparable with an equal concentration of ciprofloxacin $\mathrm{HCl}$. Results showed that encapsulation of Cip. $\mathrm{HCl}$ led to enhancement of the antibacterial activity of the drug on both Gram positive and Gram negative bacteria as indicated by the increase in inhibition zones diameters.

Table (1): Composition of different suggested formulae of ciprofloxacin $\mathrm{HCl}$ microspheres using Eudragit RS 100:

\begin{tabular}{|c|c|c|c|c|}
\hline $\begin{array}{c}\text { Formula } \\
\text { No. }\end{array}$ & $\begin{array}{c}\text { Drug } \\
(\mathrm{g})\end{array}$ & $\begin{array}{c}\text { Eudragit } \\
\text { RS 100 } \\
(\mathrm{g})\end{array}$ & $\begin{array}{c}\text { Speed } \\
(\mathrm{rpm})\end{array}$ & $\begin{array}{c}\text { Span } \\
80(\%)\end{array}$ \\
\hline 1 & 1 & 2 & 500 & 1 \\
\hline 2 & 1 & 2 & 700 & 1 \\
\hline 3 & 1 & 2 & 500 & 1.5 \\
\hline 4 & 1 & 2 & 700 & 1.5 \\
\hline 5 & 1 & 3 & 500 & 1 \\
\hline 6 & 1 & 3 & 700 & 1 \\
\hline 7 & 1 & 3 & 500 & 1.5 \\
\hline 8 & 1 & 3 & 700 & 1.5 \\
\hline
\end{tabular}

Table (2): Production yield and drug content $(\%) \pm \mathrm{SD}$ of ciprofloxacin $\mathrm{HCl}$ microspheres:

\begin{tabular}{|c|c|c|c|}
\hline $\begin{array}{c}\text { Formula } \\
\text { No. }\end{array}$ & $\begin{array}{c}\text { Drug: } \\
\text { polymer }\end{array}$ & $\begin{array}{c}\text { Production } \\
\text { yield }(\%) \pm \\
\text { SD }\end{array}$ & $\begin{array}{c}\text { Drug content } \\
(\%) \pm \text { SD }\end{array}$ \\
\hline 1 & $1: 2$ & $94.40 \pm 0.65$ & $93.24 \pm 3.14$ \\
\hline 2 & $1: 2$ & $92.77 \pm 1.20$ & $83.80 \pm 0.55$ \\
\hline 3 & $1: 2$ & $93.44 \pm 0.44$ & $97.80 \pm 6.13$ \\
\hline 4 & $1: 2$ & $98.31 \pm 0.80$ & $91.94 \pm 2.93$ \\
\hline 5 & $1: 3$ & $92.80 \pm 0.20$ & $73.17 \pm 2.18$ \\
\hline 6 & $1: 3$ & $92.90 \pm 1.60$ & $94.89 \pm 8.44$ \\
\hline 7 & $1: 3$ & $93.12 \pm 2.25$ & $96.20 \pm 8.06$ \\
\hline 8 & $1: 3$ & $90.26 \pm 1.40$ & $94.68 \pm 1.48$ \\
\hline
\end{tabular}




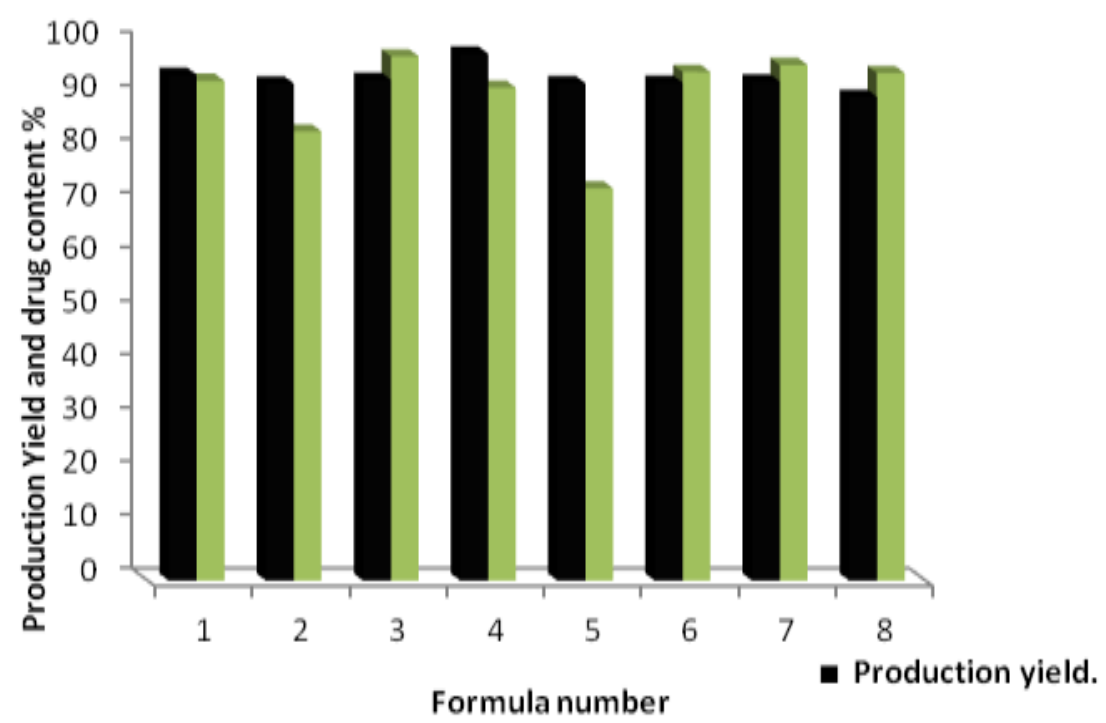

Figure (1): A histogram showing the production yield and drug content (\%) of the microspheres.
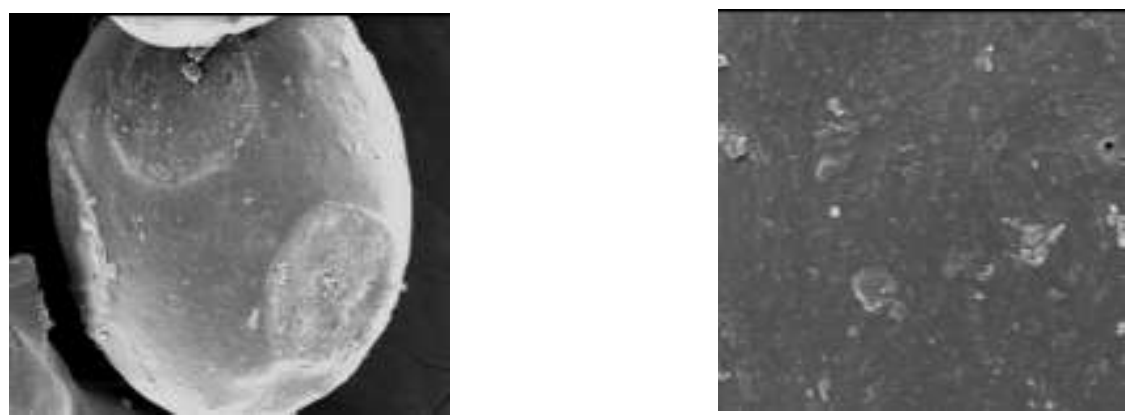

Figure ( $\left.2_{a}\right)$ : Scanning electron micrographs of ciprofloxacin $\mathrm{HCl}$ microspheres.

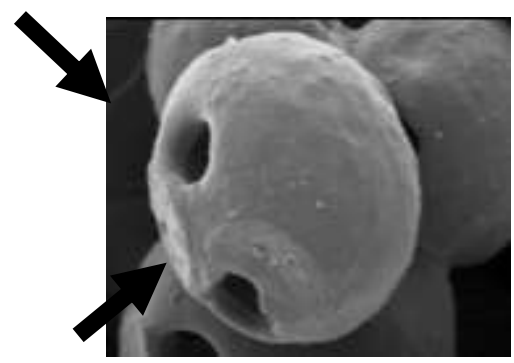

Figure $\left(\mathbf{2}_{\mathbf{b}}\right)$ : A scanning electron micrograph of formula number 4 showing aggregates and some pores (the arrows refer to the pores). 


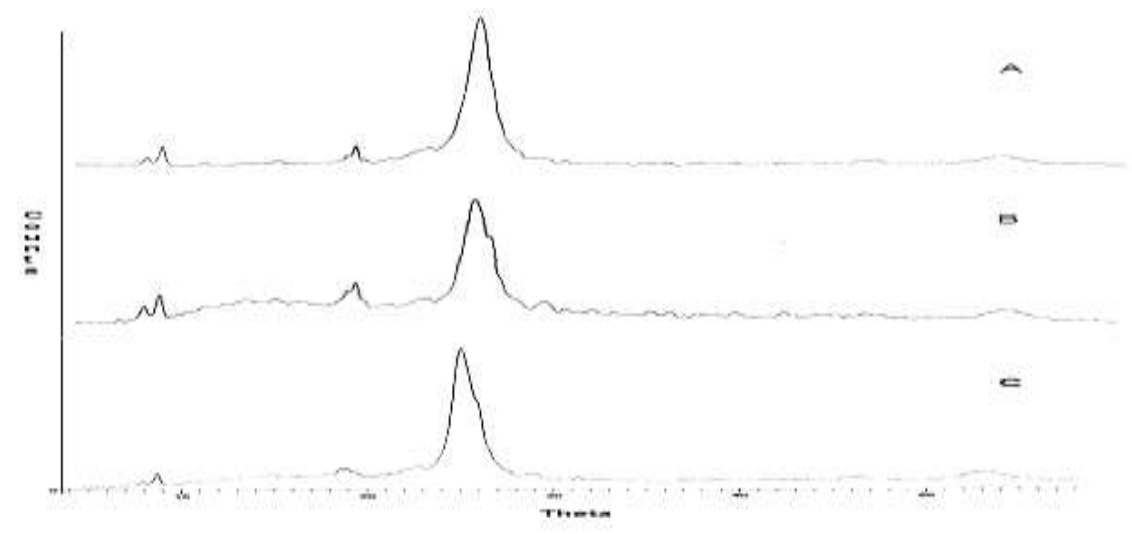

Figure (3): $\mathrm{X}$ ray diffractometry of pure ciprofloxacin $\mathrm{HCl}(\mathrm{A})$, physical mixture (B), and Cip. HCl-Eudragit RS 100 microspheres formulation (C).

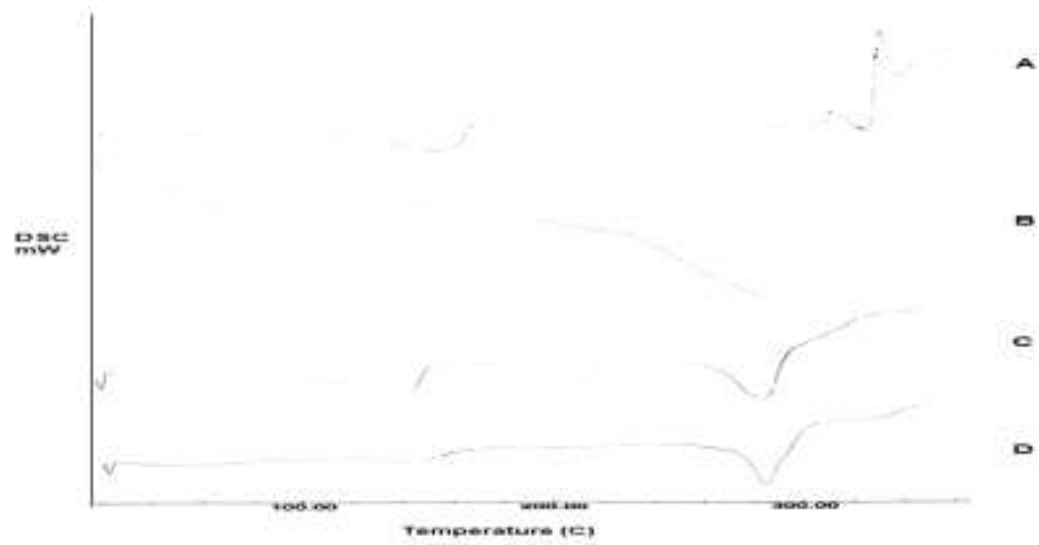

Figure (4): Thermograms of pure ciprofloxacin $\mathrm{HCl}$ (A), pure Eudragit $\mathrm{RS} 100$ (B), Cip. HCl-Eudragit RS 100 physical mixture 1:2 (C) and Cip. HCl-Eudragit RS 100 microspheres (D).

Table (3): In-vitro release of ciprofloxacin HCl-Eudragit RS 100 microspheres:

\begin{tabular}{|c|c|c|c|c|c|c|c|c|c|}
\hline \multirow{2}{*}{$\begin{array}{c}\mathbf{p H} \\
\text { value }\end{array}$} & \multirow{2}{*}{$\begin{array}{c}\text { Time } \\
\text { (min.) }\end{array}$} & \multicolumn{8}{|c|}{ Cumulative \% ciprofloxacin $\mathrm{HCl}$ release } \\
\hline & & F1 & F2 & F3 & F4 & F5 & F6 & F7 & F8 \\
\hline \multirow{7}{*}{1.2} & 0 & 0.000 & 0.000 & 0.000 & 0.000 & 0.000 & 0.000 & 0.000 & 0.000 \\
\hline & 15 & 4.640 & 18.79 & 6.310 & 9.340 & 9.540 & 11.32 & 10.11 & 7.560 \\
\hline & 30 & 5.870 & 24.21 & 10.24 & 15.61 & 12.17 & 13.54 & 13.02 & 10.23 \\
\hline & 45 & 6.868 & 29.11 & 15.21 & 27.34 & 12.33 & 15.29 & 14.98 & 13.72 \\
\hline & 60 & 11.25 & 33.15 & 21.34 & 41.02 & 14.37 & 18.59 & 16.23 & 16.54 \\
\hline & 90 & 18.35 & 38.42 & 26.34 & 52.31 & 14.92 & 22.34 & 17.93 & 19.24 \\
\hline & 120 & 26.34 & 41.5 & 33.25 & 67.24 & 16.11 & 24.33 & 19.24 & 21.34 \\
\hline \multirow{7}{*}{7.4} & 150 & 35.26 & 45.19 & 44.24 & 75.24 & 23.45 & 26.20 & 28.33 & 28.34 \\
\hline & 180 & 43.25 & 50.22 & 58.36 & 84.21 & 32.54 & 30.87 & 35.26 & 33.21 \\
\hline & 240 & 58.31 & 56.13 & 68.34 & 91.24 & 45.35 & 41.34 & 42.66 & 45.36 \\
\hline & 300 & 65.45 & 62.31 & 75.35 & 98.65 & 51.63 & 52.22 & 53.12 & 60.21 \\
\hline & 360 & 71.68 & 75.05 & 87.93 & 100.0 & 62.25 & 60.23 & 59.32 & 68.32 \\
\hline & 420 & 80.65 & 81.32 & 94.65 & 100.0 & 69.34 & 68.93 & 66.51 & 76.36 \\
\hline & 480 & 84.35 & 90.21 & 100.0 & 100.0 & 75.26 & 77.92 & 77.63 & 85.26 \\
\hline
\end{tabular}




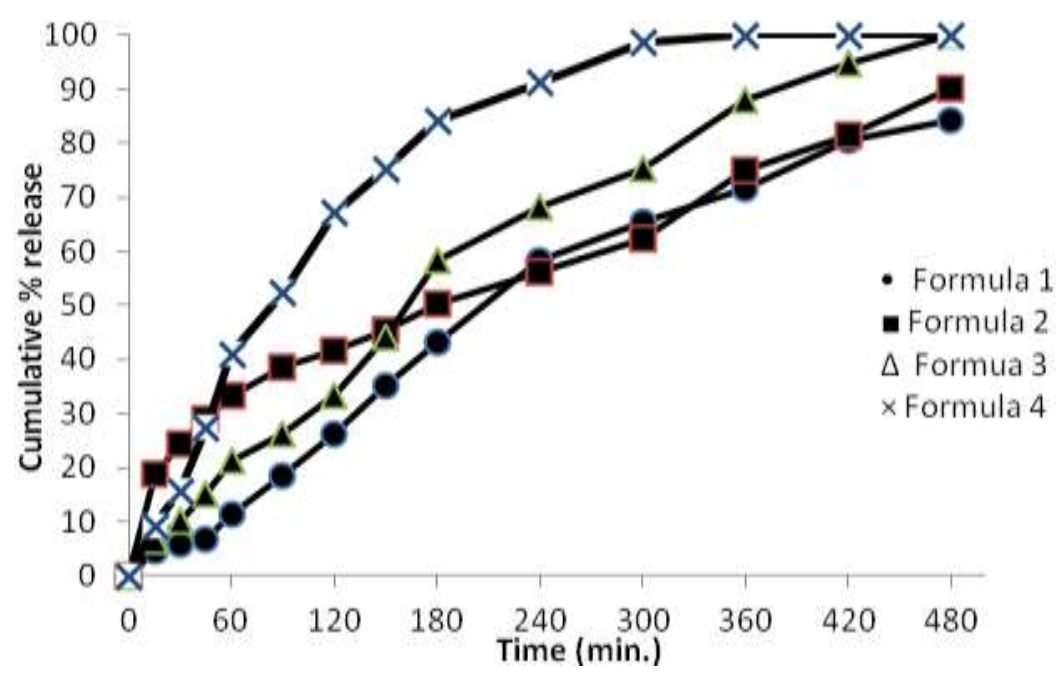

Figure (5): In-vitro release profile of ciprofloxacin $\mathrm{HCl}$-Eudragit RS 100 microspheres prepared at drug to polymer ratio (1:3).

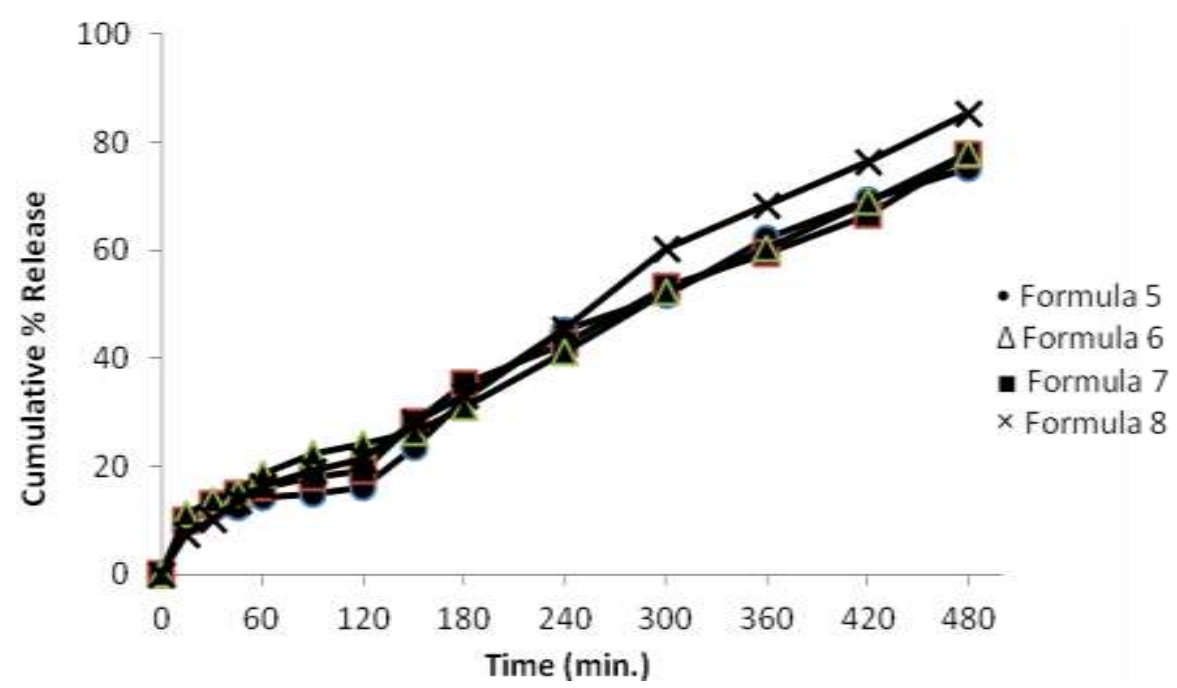

Figure (6): In-vitro release profile of ciprofloxacin HCl-Eudragit RS 100 microspheres prepared at drug to polymer ratio (1:3).

Table (4): Kinetic parameters for the in-vitro release of ciprofloxacin $\mathrm{HCl}$-Eudragit RS 100 microspheres according to the most suitable order or model:

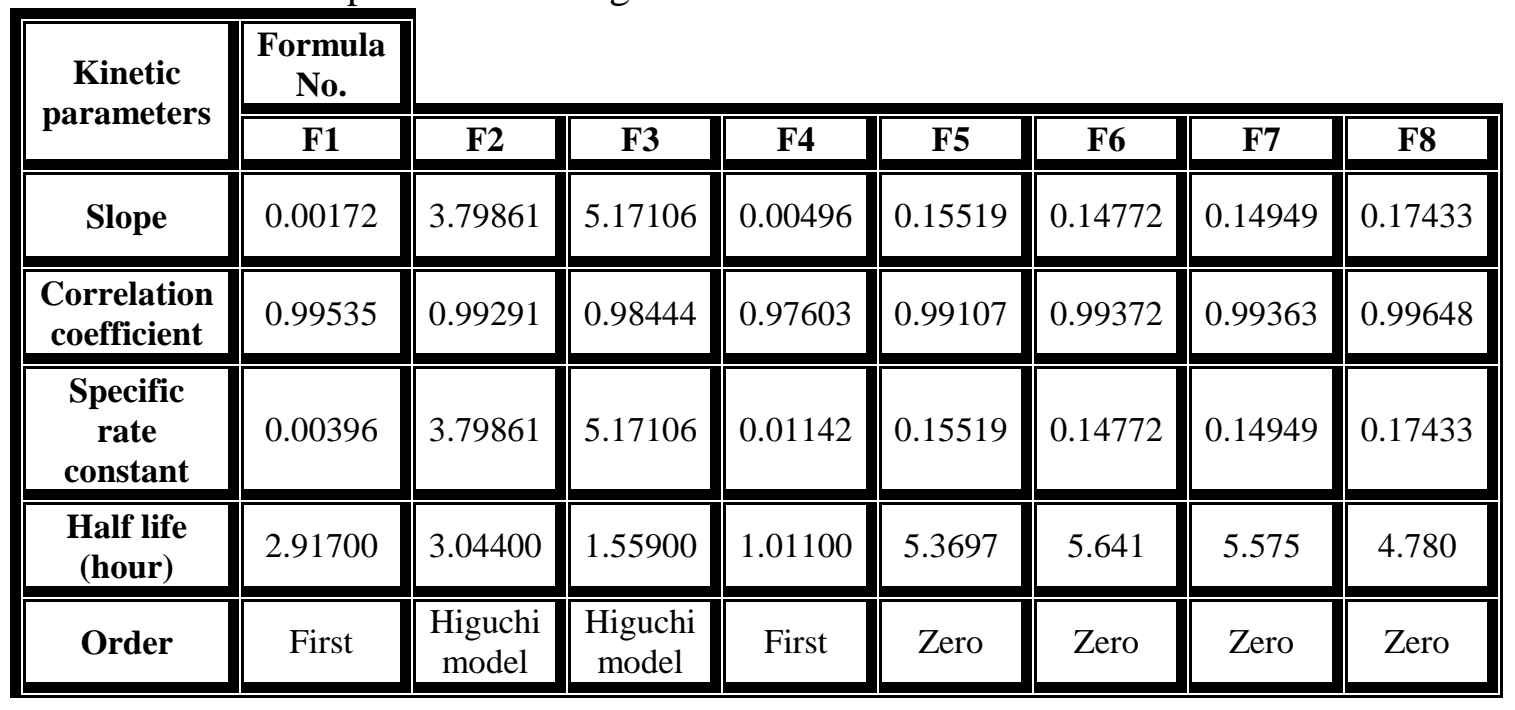


Table (5): Inhibition zones diameters of pure Cip. $\mathrm{HCl}$ (20) and Cip. HCl-Eudragit microspheres (21) on Streptococcus faecalis (representing Gram positive strains) and Escherichia coli (representing Gram negative bacteria).

\begin{tabular}{|c|c|c|}
\hline \multirow{2}{*}{ Sample } & \multicolumn{2}{|c|}{ Inhibition zone diameter (mm/sample) } \\
\cline { 2 - 3 } & Escherichia coli $\left(\mathbf{G}^{-}\right)$ & $\begin{array}{c}\text { Streptococcus faecalis } \\
\left(\mathbf{G}^{+}\right)\end{array}$ \\
\hline (20) Pure Cip. HCl & 26 & 29 \\
\hline (21) Cip. HCl- & & \\
Eudragit & 29 & 32 \\
\end{tabular}

Where $G^{-}$refers to Gram negative bacterial strains and $G^{+}$refers to those of Gram positive.

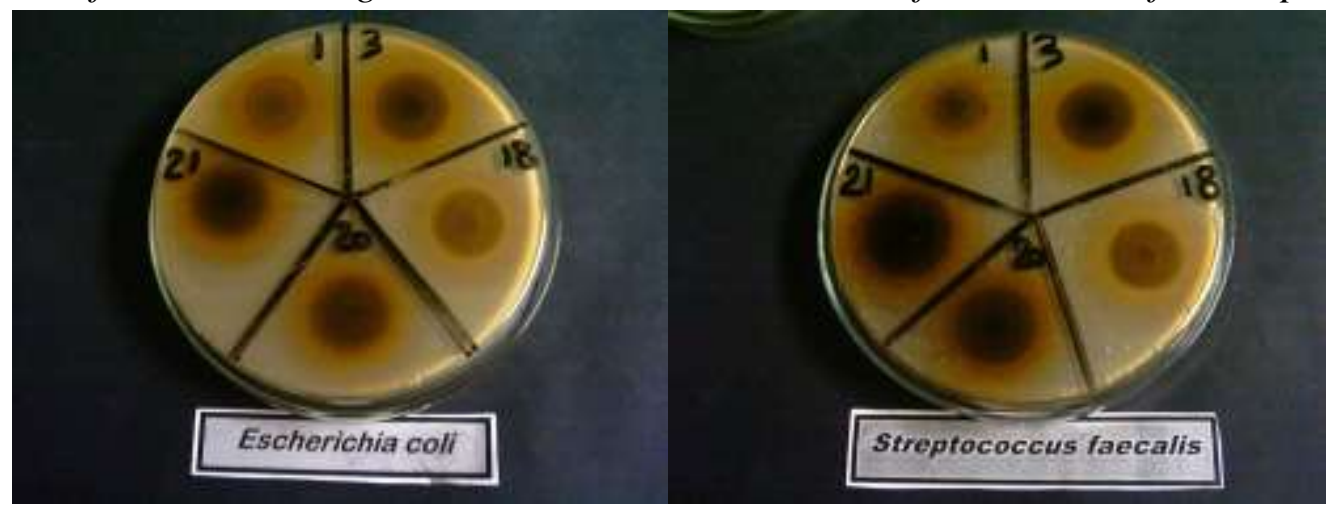

Figure (7): The antibacterial activity of the pure drug (20),pure Eudragit RS 100 (1),and Cip. HCl-Eudragit RS 100 microspheres (21) using E. coli and Streptococcus faecalis strains.

\section{CONCLUSION}

Using ciprofloxacin hydrochloride as a water soluble model drug, Eudragit RS 100 microspheres were produced by emulsion-solvent evaporation method. The production yield and drug loading were high. The results of drug release showed that the amount of ciprofloxacin hydrochloride released increased with an increase in the emulsifier concentration and decreased as the amount of the polymer increased. In addition, the prepared microspheres have superior effectiveness to inhibit the growth of bacteria compared to the free ciprofloxacin.

\section{REFERENCES}

Benita, S.; (1996): in "Microencapsulation: Methods and Industrial Applications", by Marcel Dekker, New York, page 1.

Huang, X.; and Brazel, C. S.; 2001): Journal of Controlled Release, 73, 121-136.

Buntnera, B.; Nowaka, M.; Kasperczyk, J.; Rybac, M.; Griebc, P.; Walskic, M.; skid, D. P.; and Bero, M.; (1998) Journal of Controlled Release, 56, 159-167. 
Jameela, S. R.; Kumary, T. V.; Lac, A. V.; and Jayakrishnan, A.; (1998): Journal of Controlled Release, 52, 17-24.

Duarte, A. R.; , Costa, M. S.; , Simplicio, A. L.; Cardoso, M. M.; and Duarte, C. M.; (2006): International Journal of Pharmaceutics, 308, 168-174.

Crump, B.; Wise, R.; and Dent, J.; (1983): Antimicrobial Agents and Chemotherapy, 26, 784-790, (1983).

Yu, W. P., Wong, J. P., and Chang, T. M., (1999): Artificial Cells, Blood Substitutes, and Biotechnology, 27, $263-278$.

Martinez, F.; Lairion, M. B.; Pena, P. D.; and Nacucchio, M. C. (1997): Journal of Microencapsulation, 14, 155-161.

Verma, A.; Tripathy, A.; Saraf, A. S.; and Saraf, S.; (2010): International Journal of Pharmacy and Pharmaceutical Sciences. 2, 44- 48.

Abd El-rasoul, S.; (2007): PH. D. Thesis, Al Azhar University, Assiut, Egypt.

Kondo, A.; (1979): in "Microcapsule Processing and Technology" Marcel Dekker, Inc., New York, 145.

National Committee for Clinical Laboratory Standards. (2002): Performance Standards for antimicrobial susceptibility testing. $8^{\text {th }}$ Informational Supplement. M100 S12. National Committee for Clinical Laboratory Standards, Villanova, Pa.

Zidan, A. S.; Sammour, O. A.; Hammad, M. A.; and Megrab, N. A.; (2006): American Association of Pharmaceutical Scientists (AAPS), 7, 1-9.

Wang, Q.; Dong, Z.; Du, Y.; and Kennedy, F.; (2007): Carbohydrate Polymers, 69, 336343.

Salaun, F.; Devaux, E.; Bourbigot, S.; and Rumeau, P.; (2008): Carbohydrate Polymers, 73, 231-240.

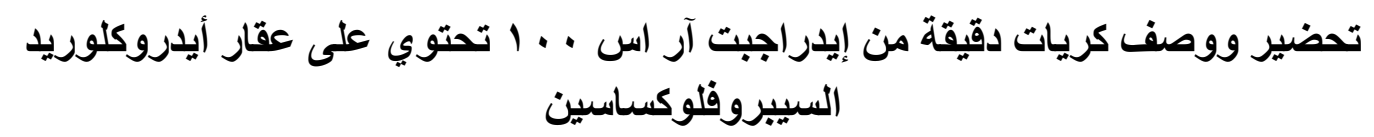

فها محمد نشأت إمام - خالا إسماعيل صالح - محمد أحمد أمين درويش - جمال محمد سلطان زايد

قسم الصيدلانيات و الصيدلة الصناعية ـ كلية الصيدلة ـجامعة الأز هر فرع أسـيوط

نالت الأنظمة الدوائية الموجهة اهتماما كبير ا في السنوات الأخيرة حيث إنها توفر تحكما في تركيز الدواء في الجسم

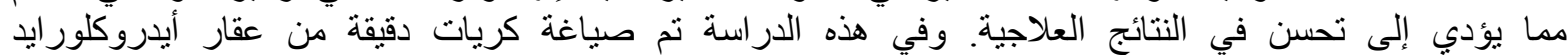

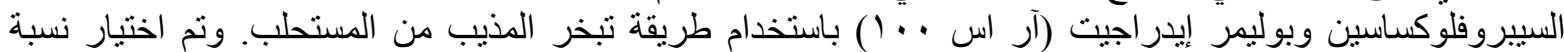

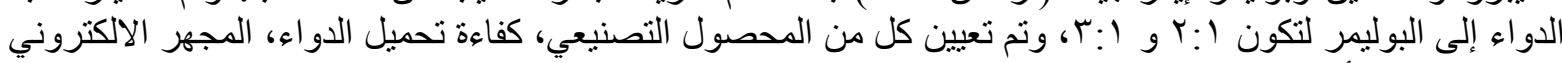

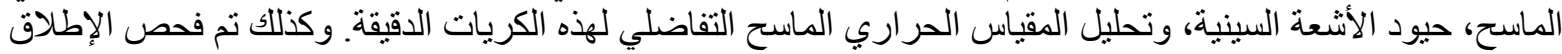

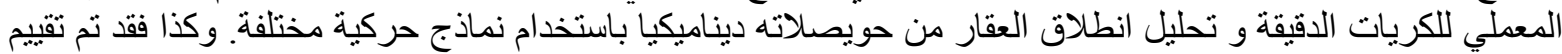

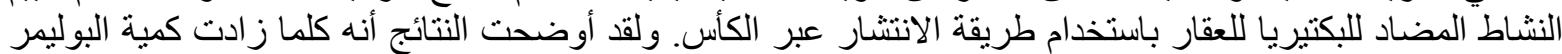

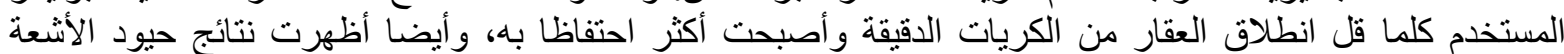

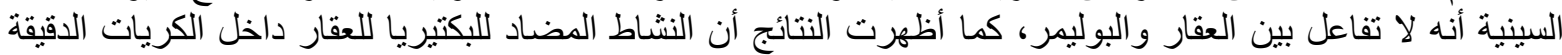
كان أفضل منه عن استخدام العقار منفردا. 